\title{
Fat cell enlargement is an independent marker of insulin resistance and 'hyperleptinaemia'
}

\author{
M. Lundgren • M. Svensson • S. Lindmark • \\ F. Renström $\cdot$ T. Ruge $\cdot$ J. W. Eriksson
}

Received: 19 September 2006 / Accepted: 16 November 2006 / Published online: 10 January 2007

(C) Springer-Verlag 2007

\begin{abstract}
Aims/hypothesis The aim of this study was to explore whether fat cell size in human subcutaneous and omental adipose tissue is independently related to insulin action and adipokine levels.

Materials and methods Fat cells were prepared from abdominal subcutaneous biopsies obtained from 49 type 2 diabetic and 83 non-diabetic subjects and from omental biopsies obtained from 37 non-diabetic subjects. Cell size and insulin action on glucose uptake capacity in vitro were assessed in isolated fat cells. Insulin sensitivity in vivo was assessed with euglycaemic-hyperinsulinaemic clamps. Fasting blood samples were collected and adipokines and NEFA were measured.

Results Negative correlations were found between subcutaneous fat cell size and insulin sensitivity assessed as $M$-value during clamp and as insulin action on glucose uptake in fat cells in vitro. This was seen in non-diabetic subjects after including age, sex and BMI in the analyses. No such relationship was found in type 2 diabetic subjects. In both groups, subcutaneous fat cell size correlated positively and independently with plasma levels of leptin but not to any of the other assessed adipokines. In nondiabetic subjects, omental fat cell size was independently
\end{abstract}

M. Lundgren $(\bowtie) \cdot M$. Svensson $\cdot S$. Lindmark $\cdot$ F. Renström

T. Ruge $\cdot$ J. W. Eriksson

Department of Medicine, UKBF, Umeå University Hospital,

Umeå, Sweden

e-mail: magdalena.lundgren@medicin.umu.se

T. Ruge

Department of Surgery, Umeå University Hospital,

Umeå, Sweden and negatively correlated with insulin action in subcutaneous, but not omental, fat cells in vitro.

Conclusions/interpretation Fat cell enlargement is associated with insulin resistance in non-diabetic individuals independently of BMI. This was not seen in type 2 diabetic subjects, suggesting that after development of type 2 diabetes other factors, not related to fat cell size, become more important for the modulation of insulin resistance.

Keywords Adipocytes - Adipokines · Fat cell size . Glucose uptake · Insulin resistance $\cdot$ Leptin · Type 2 diabetes

\section{Abbreviations \\ HOMA- homeostasis model assessment of insulin IR resistance \\ MGU maximal insulin-stimulated glucose uptake rate PPARG peroxisome proliferator activated receptor $\gamma$}

\section{Introduction}

The prevalence of obesity is rapidly growing worldwide and central, intra-abdominal adiposity is strongly related to several metabolic and cardiovascular alterations such as insulin resistance, hypertension and atherosclerosis [1, 2]. In addition to fat amount and distribution, fat cell size may be independently associated with insulin resistance [3-5].

Enlargement of fat cells is found in obesity and has also been demonstrated in pre-diabetic individuals and in patients with type 2 diabetes $[3,4,6]$. A failure in recruitment of new fat cells due to impaired differentiation, possibly of genetic origin $[7,8]$, may lead to a reduction in the capacity of the adipose tissue to accumulate lipids [9]. 
This may be paralleled by enlargement of the existing fat cells and also a 'spill-over' and ectopic accumulation of lipids in other tissues, e.g. muscle and liver [9], which in turn contribute to insulin resistance [10]. This hypothesis is supported by effects following treatment with peroxisome proliferator activated receptor $\gamma$ (PPARG) agonists, e.g. rosiglitazone and pioglitazone. Such agents improve insulin resistance in patients with type 2 diabetes, despite weight gain [11], and one suggested mechanism is an activation of preadipose cell differentiation into adipocytes, i.e. recruitment of new, small fat cells [12].

In addition, the adipose tissue is an endocrine organ, releasing hormones and adipokines, e.g. adiponectin, leptin and resistin. The amount of adipokines and NEFA released may be altered in the obese state and this may be related to enlargement of fat cells [4]. For example IL-6 and leptin release from subcutaneous adipocytes seems to be related to fat cell size $[13,14]$. Thus, fat cell size may influence hormonal signalling within the adipose tissue itself and to other organs, e.g. muscle and liver, and may thereby also affect insulin sensitivity. Furthermore, local IL- 6 and TNF- $\alpha$ levels could be elevated through an inflammatory response mediated by macrophage invasion possibly promoted by enlarged fat cells that display accelerated cell death [15].

The aim of the present study was to explore whether fat cell size in the subcutaneous and omental depots, respectively, is directly related to whole-body and cellular insulin sensitivity and to plasma adipokine levels independently of body composition, and also to identify factors that influence fat cell size. In addition, comparisons were made between non-diabetic and type 2 diabetic subjects.

\section{Subjects and methods}

Subjects The study cohort consisted of 132 subjects (69 women and 63 men), 83 non-diabetic subjects and 49 type 2 diabetic subjects diagnosed according to the 1998 WHO criteria [16]. They had a wide range of age (15-87 years) and BMI (19-49 kg/m ${ }^{2}$ ). Anthropometric and biochemical characteristics of study participants are shown in Table 1. Exclusion criteria were: cancer, endocrine disorders (except for treated primary hypothyroidism) or any acute illness. Nine of the non-diabetic subjects and 11 of the type 2 diabetic subjects were on antihypertensive medication. Three non-diabetic and two type 2 diabetic subjects were being treated for primary hypothyroidism. Five nondiabetic and three type 2 diabetic women were taking postmenopausal hormone replacement treatment. Ten of the type 2 diabetic subjects were treated with diet and exercise
Table 1 Anthropometric and biochemical characteristics of the subjects

\begin{tabular}{|c|c|c|}
\hline & $\begin{array}{l}\text { Non- } \\
\text { diabetic } \\
n=83\end{array}$ & $\begin{array}{l}\text { Type } 2 \\
\text { diabetic } \\
n=49\end{array}$ \\
\hline Sex (female/male) & $48 / 35$ & $21 / 28$ \\
\hline Age (years) & $52.9 \pm 1.7$ & $58.1 \pm 1.2^{*}$ \\
\hline Subcutaneous fat cell diameter $(\mu \mathrm{m})$ & $101.3 \pm 1.3$ & $105.4 \pm 1.3^{*}$ \\
\hline $\begin{array}{l}\text { Omental fat cell diameter } \\
(\mu \mathrm{m}, n=37 / 0)\end{array}$ & $92.9 \pm 2.3$ & n.a. \\
\hline BMI $\left(\mathrm{kg} / \mathrm{m}^{2}\right)$ & $27.4 \pm 0.6$ & $28.1 \pm 0.5$ \\
\hline WHR $(n=69 / 41)$ & $0.89 \pm 0.01$ & $0.96 \pm 0.01 * * *$ \\
\hline Body fat $(\%, n=69 / 41)$ & $31.8 \pm 1.3$ & $29.8 \pm 1.3$ \\
\hline $\begin{array}{l}\text { Systolic blood pressure } \\
(\mathrm{mmHg}, n=68 / 47)\end{array}$ & $133.3 \pm 2.2$ & $135.2 \pm 2.7$ \\
\hline $\begin{array}{l}\text { Diastolic blood pressure } \\
(\mathrm{mmHg}, n=68 / 47)\end{array}$ & $79.1 \pm 1.0$ & $77.6 \pm 1.3$ \\
\hline Plasma adiponectin $(\mu \mathrm{g} / \mathrm{ml}, n=67 / 49)$ & $10.3 \pm 0.7$ & $8.0 \pm 0.7^{*}$ \\
\hline Plasma NEFA $(\mathrm{mmol} / 1, n=73 / 48)$ & $0.45 \pm 0.02$ & $0.61 \pm 0.03 * * *$ \\
\hline Plasma IL-6 (pg/ml, $n=68 / 49)$ & $2.0 \pm 0.2$ & $2.6 \pm 0.3 *$ \\
\hline Plasma leptin $(\mathrm{ng} / \mathrm{ml}, n=67 / 49)$ & $15.9 \pm 1.9$ & $12.3 \pm 1.3$ \\
\hline Plasma TNF- $\alpha(\mathrm{pg} / \mathrm{ml}, n=63 / 46)$ & $1.8 \pm 0.3$ & $2.0 \pm 0.2$ \\
\hline HbA1c $(\%, n=66 / 49)^{\text {a }}$ & $4.4 \pm 0.1$ & $7.6 \pm 0.3 * * *$ \\
\hline LDL:HDL ratio $(n=75 / 44)$ & $2.7 \pm 0.1$ & $3.2 \pm 0.2^{*}$ \\
\hline M-value $\left(\mathrm{mg} \mathrm{kg}^{-1} \min ^{-1}, n=29 / 30\right)$ & $11.1 \pm 0.7$ & $6.2 \pm 0.5^{* * *}$ \\
\hline Subcutaneous MGU $(\%, n=67 / 48)$ & $272 \pm 15$ & $192 \pm 8 * * *$ \\
\hline Omental MGU $(\%, n=27 / 0)$ & $317 \pm 26$ & n.a. \\
\hline
\end{tabular}

Data are means \pm SEM.

MGU, maximal insulin effect on adipocyte glucose uptake, per cent of basal; n.a., non applicable

$n=$ number of non-diabetic/type 2 diabetic subjects, respectively (when data not available for all subjects).

${ }^{a}$ Reference 3.9-5.3\% (Swedish MonoS standard).

* $p<0.05, * * * p<0.001$ vs non-diabetic subjects alone, 33 were on oral glucose-lowering agents and the remaining six were on insulin, alone or in combination with oral glucose-lowering agents.

Subcutaneous $(n=132)$ adipose tissue was obtained through a needle biopsy from the lower part of the abdomen after dermal local anaesthesia with lidocain (Xylocain; AstraZeneca, Södertälje, Sweden). Omental adipose tissue biopsies were performed after induction of general anaesthesia in a subset $(n=37)$ of the participants undergoing elective abdominal surgery. All subjects were fasting ( $>10 \mathrm{~h})$. Fasting blood samples were collected on the morning of the biopsy or 1-2 months after the surgical procedure, respectively. Body fat and lean body mass ( $\%$ of body weight) were determined by the bioimpedance technique (Bodystat 1500; Bodystat, Isle of Man, Great Britain) [17]. Data were obtained by pooling subjects (46 non-diabetic subjects, 48 type 2 diabetic subjects) from 
other studies performed by our group and focussing on other aspects of insulin resistance [5, 18-20], with some additional subjects (37 non-diabetic subjects and one type 2 diabetic subject) also being recruited. Subjects were included in this study if subcutaneous and/or omental fat cell size and either insulin sensitivity in vivo assessed during clamp or insulin action on glucose uptake in vitro (in either fat depot, i.e. subcutaneous or omental) or adipokine levels were available. All subjects gave their informed consent and the Umeå University Ethics Committee approved the studies.

Materials Adenosine deaminase and collagenase A were obtained from Roche Diagnostics Scand (Bromma, Sweden). Bovine serum albumin (fraction V) and $N^{6}$ ( $R$-phenyl-isopropyl)adenosine, were provided by SigmaAldrich Sweden (Stockholm, Sweden). D- $\left[\mathrm{U}-{ }^{14} \mathrm{C}\right]$ glucose (specific activity $52.1 \mathrm{MBq} / \mathrm{mg}$ ) was purchased from Amersham Pharmacia Biotech (Bucks, UK) and DMEM and Hanks' medium 199 were obtained from Invitrogen Life Technologies (Groningen, the Netherlands). Human insulin (Actrapid, $100 \mathrm{U} / \mathrm{ml}$ ) was from Novo Nordisk (Copenhagen, Denmark).

Assessment of cell size and glucose uptake in isolated adipocytes Isolated fat cells were obtained by mincing and thereafter shaking the tissue samples in polypropylene containers at $37^{\circ} \mathrm{C}$ for $1 \mathrm{~h}$ in medium 199 containing $5.6 \mathrm{mmol} / 1$ glucose, $40 \mathrm{~g} / 1 \mathrm{BSA}$ and $0.6 \mathrm{~g} / 1$ collagenase. Following collagenase digestion, cells and medium were filtered through a nylon mesh and washed four times with fresh medium before start of the glucose uptake experiments and fat cell size assessment. The size of isolated adipocytes was assessed as described by Smith et al. [21]. In brief, approximately $0.5 \mathrm{ml}$ of cell suspension was placed in a monolayer on a glass slide and the diameter of 100 consecutive cells obtained from one subject was determined with a light microscope with an inbuilt ruler. The cell size is reported as the average cell diameter $(\mu \mathrm{m})$ of 100 cells from the subcutaneous and, in a subset, also from the omental depot. As an alternative measure of cell size, the average cell volume was also calculated, assuming that adipocytes are spherical. As expected, subsequent analyses using these data displayed essentially identical results on associations between cell size and insulin sensitivity or adipokines. Therefore we only present data on cell size expressed as cell diameter.

The glucose uptake assay was performed in fresh cells, essentially as previously reported [19]. Cellassociated radioactivity was determined by scintillation counting. Under these experimental conditions glucose uptake is mainly determined by the rate of transmembrane glucose transport [22] and it is calculated as glucose clearance from the incubation medium according to the following formula:

\section{Cellular clearance of medium glucose}

$$
=\frac{\text { Cell }- \text { associated radioactivity } \times \text { Volume }}{\text { Radioactivity in medium } \times \text { Cell number } \times \text { Time }}
$$

The maximal insulin-stimulated $(1,000 \mathrm{mU} / \mathrm{l})$ glucose uptake rate (MGU) was expressed as per cent of the basal, non-stimulated glucose uptake to provide a measure of insulin action in vitro.

Blood chemistry and insulin sensitivity Commercial enzymatic kits were used to analyse adiponectin, leptin (Linco Research, St Charles, MO, USA), NEFA (Wako Chemical USA, Richmond, VA, USA), IL- 6 and TNF- $\alpha$ (R\&D Systems, Minneapolis, MN, USA). Serum insulin concentrations were measured by microparticle enzyme immunoassays (Immulite 2000, DPC, Los Angeles, CA, USA; Abbot Imx, Abbott Laboratories, Abbott Park, IL, USA). The CVs for the hormone analyses were $2.7-8.3 \%$ within assays and $3.6-9.6 \%$ between assays. For details see [20]. All other measurements were made according to routine methods at the Department of Clinical Chemistry, Umeå University Hospital. Insulin sensitivity in vivo was assessed as glucose infusion rate, i.e. the $\mathrm{M}$-value, at steady state (60-120 $\mathrm{min})$ of a 2-h euglycaemic-hyperinsulinaemic (56 $\mathrm{mU} \mathrm{m}^{-2}$ body surface area $\mathrm{min}^{-1}$ ) clamp. This procedure was performed as previously described in detail $[20,23]$.

Statistical analyses Statistical analyses were performed using the SPSS package (version 11) (SPSS, Chicago, IL, USA). Data are presented as means \pm SEM. The following variables were logarithmically ( $\ln \log$ ) transformed due to skewed distributions: MGU in subcutaneous cells, TNF- $\alpha$, IL-6 and leptin. Differences between groups were analysed by one-way ANOVA. Univariate linear regressions were used to assess associations between subcutaneous and omental fat cell size and other variables (subcutaneous and omental MGU, M-value, $\mathrm{HbA}_{1 \mathrm{c}}$, adiponectin, IL-6, leptin, TNF- $\alpha$, NEFA, LDL:HDL ratio, systolic and diastolic blood pressure, BMI, WHR, \% body fat). The main focus of this study was to explore whether fat cell size in the subcutaneous and omental depots is related to adipokines and measures of insulin sensitivity after adjustment for indices of adiposity (BMI, WHR, body fat). In that part of the study, such variables were included in simple regression analyses. Variables displaying statistically significant associations in the univariate analyses were subsequently included in the multivariate step-wise regression analyses always adjusting for age and sex. The 
multivariate models with the highest adjusted $r^{2}$ value are reported. Standardized $\beta$-coefficients and the adjusted $r^{2}$ values are presented. A $p$ value of $<0.05$ was considered statistically significant.

\section{Results}

Anthropometric and biochemical characteristics Anthropometric and biochemical characteristics are presented in Table 1. Type 2 diabetic subjects were older $(p<0.05)$, had larger subcutaneous fat cells $(p<0.05)$ and higher WHR $(p<0.001), \mathrm{HbA}_{1 \mathrm{c}}(p<0.001), \mathrm{LDL}: \mathrm{HDL}$ ratio $(p<0.05)$ and plasma levels of NEFA $(p<0.001)$ and IL-6 $(p<0.05)$ than non-diabetic subjects. Type 2 diabetic subjects also had lower MGU $(p<0.001), M$-value $(p<0.001)$ and plasma adiponectin levels $(p<0.05)$ than non-diabetic subjects. There were no significant differences between non-diabetic and type 2 diabetic subjects with regard to BMI (19.0-49.3 and $21.9-33.8 \mathrm{~kg} / \mathrm{m}^{2}$, respectively), \% body fat or blood pressure (Table 1). When, after exclusion of non-diabetic subjects $<30$ years old, the groups of non-diabetic and type 2 diabetic subjects were age-matched, similar differences were found between the groups. However, the differences in subcutaneous fat cell size and levels of IL- 6 between non-diabetic and type 2 diabetic subjects were no longer statistically significant (data not shown). The basal glucose uptake rates in subcutaneous adipocytes from non-diabetic and type 2 diabetic subjects were $15.9 \pm 2.2$ and $11.9 \pm 1.2 \mathrm{fl}$ ceell $^{-1} \mathrm{~s}^{-1}$, respectively (NS), and $13.7 \pm 2.2 \mathrm{fl} \mathrm{cell}^{-1} \mathrm{~s}^{-1}$ in omental adipocytes from the non-diabetic subjects. In nondiabetic, but not in type 2 diabetic subjects, a positive association between cell size and basal glucose uptake rate per cell was found in subcutaneous $\left(r^{2}=0.13, \quad p=0.001\right)$ but not in omental adipocytes.

Predictors of subcutaneous fat cell size In all subjects, increasing age and female sex $(p=0.013$ and $p=0.042)$ were associated with subcutaneous but not with omental fat cell size.

In non-diabetic subjects, BMI, WHR, $\%$ body fat and plasma leptin levels were positively correlated and subcutaneous MGU and $M$-value were negatively correlated with subcutaneous fat cell size. In a multivariate step-wise regression model adjusting for age and sex, it was found that BMI, plasma leptin levels and $M$-value $(p=0.013$, $p=0.022$ and $p=0.043$, respectively) were independent predictors, together explaining $\sim 60 \%$ of the variation in subcutaneous fat cell size $\left(r^{2}=0.63, p<0.001\right.$ for model).

In type 2 diabetic subjects, BMI, $\%$ body fat and plasma leptin level were positively correlated with subcutaneous fat cell size, with plasma leptin level and
BMI ( $p<0.001$ and $p=0.025$, respectively) remaining in the multivariate step-wise regression model $\left(r^{2}=0.44\right.$, $p<0.001$ for model).

Subcutaneous fat cell size in relation to plasma adipokine and NEFA levels In non-diabetic subjects, subcutaneous fat cell size (Fig. 1a), BMI, \% body fat and subcutaneous MGU were all positively correlated with plasma leptin levels. In a multivariate model these factors were retained, and together they predicted $\sim 90 \%$ of the variation in plasma leptin levels $\left(r^{2}=0.89, p<0.001\right.$ for model) (Table 2). There was no association between subcutaneous fat cell size and any of the other measured adipokines (data not shown).

In type 2 diabetic subjects, as in non-diabetic subjects, subcutaneous fat cell size (Fig. 1b), BMI and \% body fat were positively correlated with plasma leptin levels. In the multivariate step-wise regression model, subcutaneous fat cell size and \% body fat were independent predictors of plasma leptin levels $\left(r^{2}=0.75, p<0.001\right.$ for model) (Table 2$)$.

No independent associations were found between subcutaneous fat cell size and fasting plasma levels of NEFA in any of the groups (data not shown) or between subcutane-

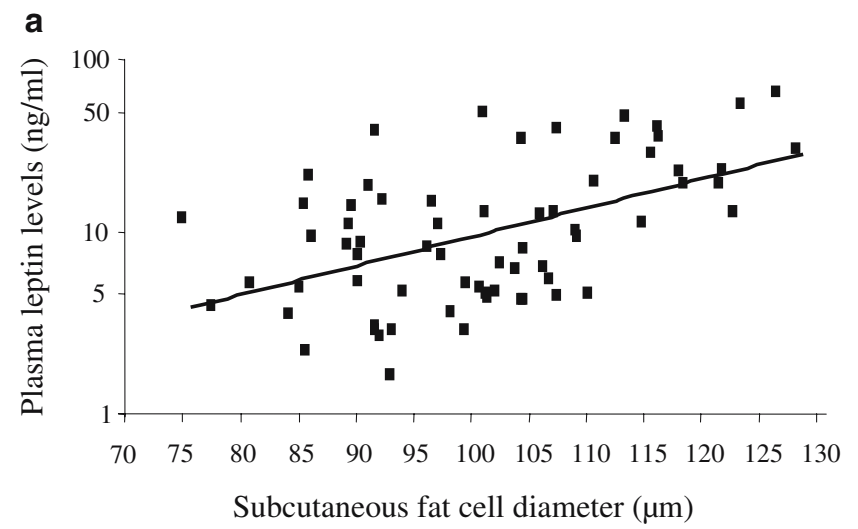

b

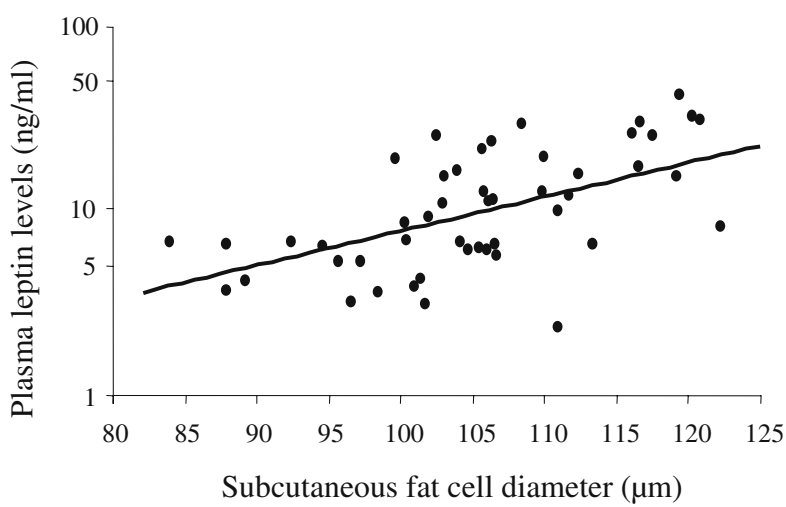

Fig. 1 Relationship between subcutaneous fat cell size (diameter, $\mu \mathrm{m}$ ) and plasma leptin levels $(\mathrm{ng} / \mathrm{ml})$ from non-diabetic (a) and type 2 diabetic subjects (b). There was a significant positive association between subcutaneous fat cell size and plasma leptin levels. $R=0.519$; $p<0.001$ (a); $R=0.597 ; p<0.001$ (b) 
Table 2 Results from multiple linear regression analyses with plasma leptin as dependent variable

\begin{tabular}{|c|c|c|c|c|}
\hline Subject group & Dependent & Independent & Standardised coefficient $\beta$ & $p$ value \\
\hline \multirow[t]{4}{*}{ Non-diabetic } & \multirow[t]{4}{*}{ Leptin } & Subcutaneous fat cell diameter & 0.321 & $<0.001$ \\
\hline & & $\%$ Body fat & 0.276 & 0.017 \\
\hline & & Subcutaneous MGU & -0.190 & 0.006 \\
\hline & & BMI & 0.166 & 0.049 \\
\hline \multirow[t]{2}{*}{ Type 2 diabetic } & \multirow[t]{2}{*}{ Leptin } & $\%$ Body fat & 0.491 & $<0.001$ \\
\hline & & Subcutaneous fat cell diameter & 0.255 & 0.009 \\
\hline
\end{tabular}

Subcutaneous MGU was assessed as per cent of basal glucose uptake in subcutaneous fat cells.

Significant associations after adjusting for age and sex are shown.

ous fat cell size and the suppressed NEFA levels during clamp (the mean value of two samples collected after 60 and $120 \mathrm{~min}$ of hyperinsulinaemia, data not shown).

Subcutaneous fat cell size in relation to insulin resistance in vitro and in vivo In non-diabetic subjects, subcutaneous fat cell size (Fig. 2a) as well as BMI, WHR and plasma leptin levels were negatively correlated with MGU in subcutaneous fat cells, and the relationship between fat cell size and MGU remained after adjustment for age, BMI and sex. In a multivariate step-wise regression model, only plasma leptin levels and WHR remained predictors of subcutaneous MGU $\left(r^{2}=0.40, p<0.001\right.$ for model) (Table 3). None of the other assessed adipokines, i.e. adiponectin, IL- 6 and TNF- $\alpha$, or NEFA levels were independently correlated with subcutaneous MGU in non-diabetic subjects. In addition, subcutaneous fat cell size (Fig. 2b) was negatively correlated with insulin resistance in vivo assessed during clamp (M-value), and for BMI, WHR and leptin there were close to significant negative associations ( $p=0.078,0.083$ and 0.052 respectively). In a multivariate model, cell size remained significantly and inversely associated with M-values $\left(r^{2}=0.17, p=0.014\right.$ for model) (Table 3).

No significant correlation was found between subcutaneous fat cell size and subcutaneous MGU or M-value in type 2 diabetic subjects $(p>0.1)$; instead BMI and WHR (not shown) were negatively correlated with MGU in subcutaneous fat cells. In the multivariate step-wise regression analysis, only BMI was an independent predictor of subcutaneous MGU $\left(r^{2}=0.23, p=0.001\right.$ for model $)$ (Table 3). Furthermore, in these subjects, WHR but not BMI was negatively correlated with the $\mathrm{M}$-value, this association remaining in the multivariate analysis $\left(r^{2}=0.11\right.$, $p=0.041$ for model) (Table 3).
Fig. 2 Relationship between subcutaneous $(\mathbf{a}, \mathbf{b})$ and omental (c) fat cell size (diameter, $\mu \mathrm{m})$ and maximal glucose uptake rate measured as per cent of basal in subcutaneous cells (a, c) and M-value (mg kg $\left.\mathrm{LBM}^{-1} \mathrm{~min}^{-1}\right)(\mathbf{b})$ in nondiabetic subjects. LBM, lean body mass. There were significant negative associations between subcutaneous fat cell size and glucose uptake rate and M-value. a $R=-0.318 ; p=0.009$; b $R=-0.450 ; p=0.014$; c $R=-0.492 ; p=0.011$
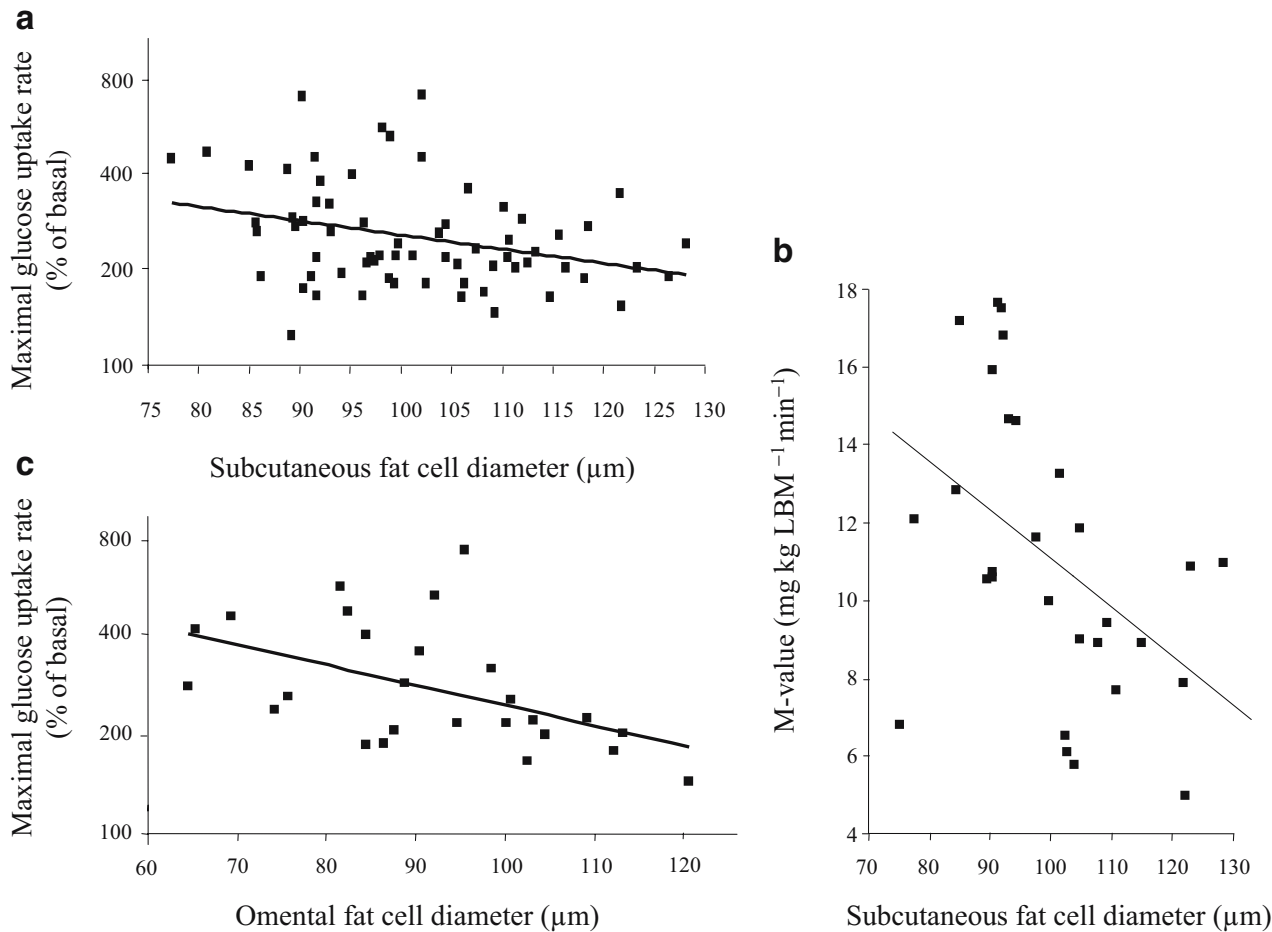
Table 3 Results from multiple linear regression analyses with the maximal subcutaneous insulin-stimulated glucose uptake (MGU) as percent of basal and $\mathrm{M}$-value as dependent variables

\begin{tabular}{|c|c|c|c|c|}
\hline Subject group & Dependent & Independent & Standardised coefficient $\beta$ & $\mathrm{p}$ value \\
\hline \multirow[t]{3}{*}{ Non-diabetic } & MGU & Leptin & -0.484 & $<0.001$ \\
\hline & & WHR & -0.483 & $<0.001$ \\
\hline & M-value & Subcutaneous fat cell diameter & -0.450 & 0.014 \\
\hline \multirow[t]{2}{*}{ Type 2 diabetic } & MGU & BMI & -0.499 & 0.001 \\
\hline & M-value & WHR & -0.376 & 0.041 \\
\hline
\end{tabular}

Factors entered as independent variables: BMI, per cent body fat, WHR, subcutaneous fat cell diameter, plasma leptin.

Significant associations after adjusting for age and sex are shown.

Omental fat cell size in relation to BMI, insulin resistance and plasma levels of adipokines and NEFA In a subgroup of non-diabetic subjects $(n=37)$, omental fat cell size was assessed following biopsies during abdominal surgery. In these subjects, BMI, WHR, diastolic blood pressure, LDL: HDL ratio and subcutaneous MGU were all correlated with omental fat cell size. In a multivariate step-wise regression model, subcutaneous MGU, LDL:HDL ratio and BMI remained predictors of omental fat cell size $\left(r^{2}=0.62\right.$, $p<0.001$ for model).

Omental fat cell size correlated negatively with subcutaneous (Fig. 2c) but not with omental MGU (not shown) and explained $\sim 20 \%$ of the variation in subcutaneous MGU $\left(r^{2}=0.21, p=0.011\right.$ for model) in a multivariate step-wise regression model. There was a near-significant association between subcutaneous fat cell size and MGU in subcutaneous fat cells in these subjects $(p=0.053)$. In these subjects insulin resistance in vivo assessed as M-value was not available. Instead, homeostasis model assessment of insulin resistance (HOMA-IR) was used as a surrogate. However, no significant association between omental fat cell size and HOMA-IR index was found in these subjects (not shown).

No significant correlation was found between omental fat cell size and the levels of leptin or any of the other assessed adipokines, i.e. IL-6, adiponectin and TNF- $\alpha$, as well as NEFA ( $n=22, p>0.1)$ (data not shown).

\section{Discussion}

In this study we tried to elucidate the possible associations between fat cell size, levels of adipokines and insulin sensitivity in non-diabetic subjects and in type 2 diabetic patients. Insulin action was assessed in fat cells with respect to glucose uptake and in vivo with the euglycaemic-hyperinsulinaemic clamp technique. We showed that subcutaneous fat cell size is associated with BMI, WNR and leptin in both non-diabetic and type 2 diabetic subjects. In non-diabetic subjects subcutaneous and omental fat cell size are independently associated with insulin resistance in vitro; moreover, there is a correlation between subcutaneous fat cell size and insulin resistance in vivo. However, other factors such as BMI, WNR and levels of leptin are also of importance. In type 2 diabetic subjects, BMI and WHR but not fat cell size, predict insulin resistance, both in vivo and in vitro. Taken together, these and previous [3, 4] observations support the idea that enlargement of fat cells may predict and possibly contribute to the development of type 2 diabetes.

Interestingly, we found a stronger association for omental than for subcutaneous fat cell size vs glucose uptake in subcutaneous fat cells, suggesting that some factor, e.g. adipokine(s), released from omental fat cells may affect insulin action in subcutaneous cells. However, we have no clear explanation of this association, since omental fat cell size did not correlate with plasma levels of any of the assessed adipokines or NEFA. Retinolbinding protein 4 released from adipose tissue has been implicated in the development of insulin resistance [24], but retinol-binding protein 4 was not assessed in this study. Glucose uptake capacity in adipose tissue is low compared with that in muscle, for example. Our finding that omental fat cell size may predict $20 \%$ of the variation in insulin action on subcutaneous glucose uptake capacity may therefore seem to be of limited physiological interest. However, as shown by Shepherd and co-workers in a study on rodents [25], modest changes in adipose tissue glucose turnover can have large secondary effects on whole-body glucose metabolism. Small alterations in subcutaneous glucose uptake capacity may therefore also be of importance in humans. Moreover, large omental cells may directly influence liver and muscle glucose utilisation via yet unknown mediators released into the circulation. Nonetheless, it is likely that a defect in cellular insulin action in adipose tissue is of importance for the development of insulin resistance in other organs, and that it thus can contribute to whole-body insulin resistance and risk of developing type 2 diabetes. However, it is not possible from this cross-sectional study to establish time relationship and causality between fat cell size and whole-body insulin resistance and type 2 diabetes. After the development of type 2 diabetes, factors other than fat cell size probably 
become more important in the promotion of insulin resistance, e.g. high NEFA and glucose levels [20].

Compared with a small fat cell, a large fat cell might not only be insulin-resistant with respect to glucose uptake capacity, but also with respect to the antilipolytic effect of insulin. If so, a large fat cell would release elevated levels of NEFA and glycerol, thereby enhancing hepatic glucose output as well as muscle and whole-body insulin resistance [26]. Surprisingly, we could not find any clear evidence for NEFA as a messenger between fat cell size and insulin resistance in the present study, since no independent relationship was found between fat cell size in either depot and plasma levels of NEFA either in the basal condition or during hyperinsulinaemia. However, these results should be interpreted with caution due to limitations in the assay for detection of low concentrations of NEFA. Furthermore, recent results from our group have shown that there was no association between fat cell size and lipolytic rate or the antilipolytic effects of insulin in vitro (M. Lundgren, J. Burén, P. Lindgren, T. Myrnäs, T. Ruge and J.W. Eriksson, unpublished data). Altogether, these findings are in line with the study by Weyer et al. [4], which showed that NEFA release does not explain the relationship between fat cell size and M-value.

The levels of leptin were dependent on body composition (BMI and \% body fat) and subcutaneous fat cell size in non-diabetic and type 2 diabetic subjects, respectively. This is in agreement with the fact that leptin is produced mainly in subcutaneous adipose tissue [27]. In nondiabetic, but not in type 2 diabetic subjects a strong relationship between leptin levels and insulin action on glucose uptake in subcutaneous fat cells was also found. Previous studies have shown a relationship between in vivo insulin resistance and leptin levels [28, 29], and leptin has been shown to cause insulin resistance in rat fat cells in vitro [30]. Since leptin was associated with subcutaneous fat cell size as well as insulin resistance in vitro in this study, leptin may serve as a marker and possibly be a link between fat cell size and insulin resistance. On the other hand, fat cell enlargement could also develop as a consequence of leptin resistance, which could lead to elevated diacylglycerol acyltransferase 2 activity and triacylglycerol assembly [31].

Adiponectin has previously been shown to be negatively associated with adiposity as reviewed in Fantuzzi et al. [32] and it is known that adiposity is positively associated with fat cell size. In that context it is surprising that we could not find any relation between subcutaneous or omental fat cell size and plasma adiponectin levels. The present data cannot provide answers on this issue, besides suggesting that other factors than fat cell size regulate adiponectin secretion.

IL- 6 and TNF- $\alpha$ have been implicated in the development of insulin resistance [33-35] and adipocyte function in vitro [36], and the local adipose tissue levels of these cytokines could possibly be elevated due to macrophage aggregation in response to elevated fat cell death following enlargement of fat cells [15]. However, the importance of adipocyte-derived TNF- $\alpha$ and IL- 6 for insulin resistance is still under debate [34]. In this study we could not find any independent associations between plasma levels of TNF- $\alpha$ or IL-6 and fat cell size or insulin resistance. As suggested previously, these adipokines may have mainly paracrine effects $[14,37]$.

Large fat cells may merely be a sign of reduced capacity in adipose tissue to recruit and differentiate new fat cells. This propensity can be of genetic origin and appears to covary with insulin resistance [7, 8]. Impaired expression of genes regulating adipogenesis, e.g. PPARG and sterol regulatory element binding transcription factor 1 , has been shown to be related to insulin resistance [38] and treatment with thiazolidinediones improves insulin sensitivity in parallel with enhancing the differentiation of new, small adipocytes [11, 39]. Other suggested mechanisms linking fat cell size and insulin resistance are alterations in the expression pattern of immune-related genes and an altered cholesterol balance in cellular membranes of enlarged adipocytes [40, 41]. Furthermore, a combined excess in energy intake and impaired adipogenesis could be manifested as enlarged fat cells and NEFA spill-over from adipose tissue to muscle and liver, where they accumulate as ectopic triacylglycerols. This is found in obese subjects and subjects with type 2 diabetes $[10,42]$ and is associated with reduced insulin sensitivity [43-46].

There are obviously limitations to this study. It is based on a cohort consisting of subjects pooled from other studies. Omental fat biopsies were obtained only from non-diabetic subjects and hence, no comparisons can be made between non-diabetic and type 2 diabetic subjects regarding this fat depot. In addition, the subjects donating omental fat samples underwent a surgical procedure. Even though the blood samples from this subgroup were obtained 1-2 months after the surgery, there might still be some changes in blood chemistry related to the surgical procedure. Moreover, whole-body insulin sensitivity assessments with glucose clamps were available only in a subset of participants (29 non-diabetic subjects and 30 type 2 diabetic subjects), and it was not performed in the patients undergoing surgery.

In summary, subcutaneous and omental fat cell size is related to cellular insulin resistance in subcutaneous fat cells as well as to whole-body insulin resistance in nondiabetic subjects. The mechanisms behind these relationships are not entirely clear, but adipokines with autocrine, paracrine or endocrine effects could be involved. The levels of leptin show a strong relationship with both subcutaneous fat cell size and insulin resistance and may therefore be a 
link between the two. Three hypotheses could be suggested based on the present and previous findings, namely that enlarged fat cells are a manifestation of: (1) (over)filled energy stores; (2) genetically determined disability to differentiate new fat cells; or (3) a local inflammatory and/or endocrine alteration in adipose tissue. All of these might contribute to increased fat cell size, lipid spill-over and an altered adipose-derived signalling to other tissues, thereby promoting insulin resistance.

Acknowledgements We gratefully acknowledge the assistance of E. Strömqvist-Engbo, K. Öjbrandt, P. Lindgren, T. Myrnäs, the staff at the Departments of Surgery and Gynaecology (C-OP 2 and C-OP 3) and at the Metabolic Unit at Umeå University Hospital for their skilful work and assistance during this project. Financial support was given by the Swedish Research Council (Medicine, project 14287), the Swedish Diabetes Association, AstraZeneca R\&D, the Faculty of Medicine at Umeå University and the following foundations: Novo Nordisk, Elsa and Folke Sahlberg, Sigurd and Elsa Golje, and Torsten and Ragnar Söderberg.

Duality of interest J. Eriksson is an advisor at AstraZeneca R\&D.

\section{References}

1. Bjorntorp P (1988) Abdominal obesity and the development of noninsulin-dependent diabetes mellitus. Diabetes Metab Rev 4:615-622

2. Wajchenberg BL (2000) Subcutaneous and visceral adipose tissue: their relation to the metabolic syndrome. Endocr Rev 21:697-738

3. Eriksson JW, Smith U, Waagstein F, Wysocki M, Jansson PA (1999) Glucose turnover and adipose tissue lipolysis are insulinresistant in healthy relatives of type 2 diabetes patients: is cellular insulin resistance a secondary phenomenon? Diabetes 48:15721578

4. Weyer C, Foley JE, Bogardus C, Tataranni PA, Pratley RE (2000) Enlarged subcutaneous abdominal adipocyte size, but not obesity itself, predicts type II diabetes independent of insulin resistance. Diabetologia 43:1498-1506

5. Buren J, Lindmark S, Renstrom F, Eriksson JW (2003) In vitro reversal of hyperglycemia normalizes insulin action in fat cells from type 2 diabetes patients: is cellular insulin resistance caused by glucotoxicity in vivo? Metabolism 52:239-245

6. Paolisso G, Tataranni PA, Foley JE, Bogardus C, Howard BV, Ravussin E (1995) A high concentration of fasting plasma nonesterified fatty acids is a risk factor for the development of NIDDM. Diabetologia 38:1213-1217

7. Weyer C, Wolford JK, Hanson RL et al (2001) Subcutaneous abdominal adipocyte size, a predictor of type 2 diabetes, is linked to chromosome 1q21-q23 and is associated with a common polymorphism in LMNA in Pima Indians. Mol Genet Metab $72: 231-238$

8. Wolford JK, Hanson RL, Bogardus C, Prochazka M (2001) Analysis of the lamin $\mathrm{A} / \mathrm{C}$ gene as a candidate for type II diabetes susceptibility in Pima Indians. Diabetologia 44:779-782

9. Danforth E Jr (2000) Failure of adipocyte differentiation causes type II diabetes mellitus? Nat Genet 26:13

10. McGarry JD, Dobbins RL (1999) Fatty acids, lipotoxicity and insulin secretion. Diabetologia 42:128-138
11. Shadid S, Jensen MD (2003) Effects of pioglitazone versus diet and exercise on metabolic health and fat distribution in upper body obesity. Diabetes Care 26:3148-3152

12. Okuno A, Tamemoto H, Tobe K et al (1998) Troglitazone increases the number of small adipocytes without the change of white adipose tissue mass in obese Zucker rats. J Clin Invest 101:1354-1361

13. Lonnqvist F, Nordfors L, Jansson M, Thorne A, Schalling M, Arner P (1997) Leptin secretion from adipose tissue in women. Relationship to plasma levels and gene expression. J Clin Invest 99:2398-2404

14. Sopasakis VR, Sandqvist M, Gustafson B et al (2004) High local concentrations and effects on differentiation implicate interleukin6 as a paracrine regulator. Obes Res 12:454-460

15. Cinti S, Mitchell G, Barbatelli G et al (2005) Adipocyte death defines macrophage localization and function in adipose tissue of obese mice and humans. J Lipid Res 46:2347-2355

16. Alberti KG, Zimmet PZ (1998) Definition, diagnosis and classification of diabetes mellitus and its complications. Part 1: diagnosis and classification of diabetes mellitus provisional report of a WHO consultation. Diabet Med 15:539-553

17. Lukaski HC, Bolonchuk WW, Hall CB, Siders WA (1986) Validation of tetrapolar bioelectrical impedance method to assess human body composition. J Appl Physiol 60:1327-1332

18. Eriksson JW, Buren J, Svensson M, Olivecrona T, Olivecrona G (2003) Postprandial regulation of blood lipids and adipose tissue lipoprotein lipase in type 2 diabetes patients and healthy control subjects. Atherosclerosis 166:359-367

19. Lundgren M, Buren J, Ruge T, Myrnas T, Eriksson JW (2004) Glucocorticoids down-regulate glucose uptake capacity and insulin-signaling proteins in omental but not subcutaneous human adipocytes. J Clin Endocrinol Metab 89:2989-2997

20. Lindmark S, Buren J, Eriksson JW (2006) Insulin resistance, endocrine function and adipokines in type 2 diabetes patients at different glycaemic levels: potential impact for glucotoxicity in vivo. Clin Endocrinol (Oxf) 65:301-309

21. Smith U, Sjostrom L, Bjornstorp P (1972) Comparison of two methods for determining human adipose cell size. J Lipid Res 13:822-824

22. Kashiwagi A, Verso MA, Andrews J, Vasquez B, Reaven G, Foley JE (1983) In vitro insulin resistance of human adipocytes isolated from subjects with noninsulin-dependent diabetes mellitus. J Clin Invest 72:1246-1254

23. Lindmark S, Wiklund U, Bjerle P, Eriksson JW (2003) Does the autonomic nervous system play a role in the development of insulin resistance? A study on heart rate variability in first-degree relatives of Type 2 diabetes patients and control subjects. Diabet Med 20:399-405

24. Graham TE, Yang Q, Bluher M et al (2006) Retinol-binding protein 4 and insulin resistance in lean, obese, and diabetic subjects. N Engl J Med 354:2552-2563

25. Shepherd PR, Gnudi L, Tozzo E, Yang H, Leach F, Kahn BB (1993) Adipose cell hyperplasia and enhanced glucose disposal in transgenic mice overexpressing GLUT4 selectively in adipose tissue. J Biol Chem 268:22243-22246

26. Boden G (1998) Free fatty acids (FFA), a link between obesity and insulin resistance. Front Biosci 3:169-175

27. Arner P (2001) Regional differences in protein production by human adipose tissue. Biochem Soc Trans 29:72-75

28. Segal KR, Landt M, Klein S (1996) Relationship between insulin sensitivity and plasma leptin concentration in lean and obese men. Diabetes 45:988-991

29. Jansson PA, Eliasson B, Lindmark S, Eriksson JW (2002) Endocrine abnormalities in healthy first-degree relatives of type 2 diabetes patients-potential role of steroid hormones and leptin in the development of insulin resistance. Eur J Clin Invest 32:172-178 
30. Muller G, Ertl J, Gerl M, Preibisch G (1997) Leptin impairs metabolic actions of insulin in isolated rat adipocytes. J Biol Chem 272:10585-10593

31. Suzuki R, Tobe K, Aoyama M et al (2005) Expression of DGAT2 in white adipose tissue is regulated by central leptin action. J Biol Chem 280:3331-3337

32. Fantuzzi G (2005) Adipose tissue, adipokines, and inflammation. J Allergy Clin Immunol 115:911-919

33. Lofgren P, van Harmelen V, Reynisdottir S et al (2000) Secretion of tumor necrosis factor-alpha shows a strong relationship to insulin-stimulated glucose transport in human adipose tissue. Diabetes 49:688-692

34. Bastard JP, Maachi M, Van Nhieu JT et al (2002) Adipose tissue IL-6 content correlates with resistance to insulin activation of glucose uptake both in vivo and in vitro. J Clin Endocrinol Metab 87:2084-2089

35. Rotter V, Nagaev I, Smith U (2003) Interleukin-6 (IL-6) induces insulin resistance in 3T3-L1 adipocytes and is, like IL-8 and tumor necrosis factor-alpha, overexpressed in human fat cells from insulin-resistant subjects. J Biol Chem 278:45777-45784

36. Gustafson B, Smith U (2006) Cytokines promote Wnt signaling and inflammation and impair the normal differentiation and lipid accumulation in 3T3-L1 preadipocytes. J Biol Chem 281:95079516

37. Coppack SW (2001) Pro-inflammatory cytokines and adipose tissue. Proc Nutr Soc 60:349-356

38. Yang X, Jansson PA, Nagaev I et al (2004) Evidence of impaired adipogenesis in insulin resistance. Biochem Biophys Res Commun 317:1045-1051
39. Hammarstedt A, Sopasakis VR, Gogg S, Jansson PA, Smith U (2005) Improved insulin sensitivity and adipose tissue dysregulation after short-term treatment with pioglitazone in non-diabetic, insulin-resistant subjects. Diabetologia 48:96-104

40. Le Lay S, Krief S, Farnier C et al (2001) Cholesterol, a cell sizedependent signal that regulates glucose metabolism and gene expression in adipocytes. J Biol Chem 276:16904-16910

41. Jernas M, Palming J, Sjoholm K et al (2006) Separation of human adipocytes by size: hypertrophic fat cells display distinct gene expression. Faseb J 20:1540-1542

42. Raz I, Eldor R, Cernea S, Shafrir E (2005) Diabetes: insulin resistance and derangements in lipid metabolism. Cure through intervention in fat transport and storage. Diabetes Metab Res Rev 21:3-14

43. Phillips DI, Caddy S, Ilic V et al (1996) Intramuscular triglyceride and muscle insulin sensitivity: evidence for a relationship in nondiabetic subjects. Metabolism 45:947-950

44. Krssak M, Falk Petersen K, Dresner A et al (1999) Intramyocellular lipid concentrations are correlated with insulin sensitivity in humans: a ${ }^{1} \mathrm{H}$ NMR spectroscopy study. Diabetologia 42:113-116

45. Perseghin G, Scifo P, De Cobelli F et al (1999) Intramyocellular triglyceride content is a determinant of in vivo insulin resistance in humans: a ${ }^{1} \mathrm{H}-{ }^{13} \mathrm{C}$ nuclear magnetic resonance spectroscopy assessment in offspring of type 2 diabetic parents. Diabetes 48:1600-1606

46. Ryysy L, Hakkinen AM, Goto T et al (2000) Hepatic fat content and insulin action on free fatty acids and glucose metabolism rather than insulin absorption are associated with insulin requirements during insulin therapy in type 2 diabetic patients. Diabetes 49:749-758 